\title{
Assessment of Social Sciences Teacher Candidates' Epistemological Beliefs: A Validation and Reliability Study of Scale
}

\author{
Yaşar Kop*, Özden Demir \\ Faculty of Education, Kafkas University, Turkey
}

Copyright $\bigcirc 2017$ by authors, all rights reserved. Authors agree that this article remains permanently open access under the terms of the Creative Commons Attribution License 4.0 International License

\begin{abstract}
This research mainly aims to test the reliability and validity of the Epistemological Beliefs Scale developed by Kop and Demir (2014) on the level of social sciences teaching from Faculty of Education. A total of 176 students participated in the study, which was carried out on $1^{\text {st }}, 2^{\text {nd }}, 3^{\text {rd }}$ and $4^{\text {th }}$ grades of the Social Sciences Teaching Department from the Faculty of Education in Kafkas University. An exploratory and confirmatory factor analysis was performed for the construct validity of the scale. Within the scope of reliability studies, the internal consistency (Cronbach Alpha) coefficients of the items were examined. As a result of the factor analysis, a total of 15 items consisting of the sub-dimensions that are 'a belief that learning depends on effort' (BLDE), 'a belief that learning depends on ability' (BLDA) and 'a belief of that there is only one truth' (BOOT) have been obtained. The Cronbach Alpha internal consistency coefficients for dimensions describing $47,783 \%$ of the total variance have been found to be 0.71 in total, 0.78 for the first factor, 0.69 for the second factor and 0.51 for the third factor. The compliance indicator examined as a result of confirmatory factor analysis has given satisfactory results in goodness of fit of the model and data. $(\mathrm{KMO}=0.784$; Barlett Sphericty test $\chi^{2}=610.108, \chi^{2}=122.03, \mathrm{sd}=87, \mathrm{p}<.01, \mathrm{RMSEA}=0.048$ and $\chi^{2} / \mathrm{df}=1.402$, RMR $=0.055$, STRMR $=0.066$, GFI $=0.91$, AGF $=0.88, \mathrm{NFI}=0.81, \mathrm{NNFI}=0.92, \mathrm{CFI}=0.93$, IFI $=0.93$ )
\end{abstract}

Keywords Epistemological Beliefs, Social Sciences Teaching, Learning, Science

\section{Introduction}

Science and positive beliefs about science emerge in today's world as fundamental elements in the formation of a developed society. Social science is a teaching profession that has been intertwined with the society and the scientific values and elements of the society in accordance with its nature. In addition to the fact that a good social sciences teacher should have the social and universal knowledge, constantly developing themselves in the field is a necessity in today's global world. Moreover, a positive belief on that knowledge can be gained after an effective endeavor will contribute to teachers in awareness of high level thinking processes and maturation of this understanding, in selecting the learning path they need, in entering into more qualified dialogue with their students, in planning and evaluating the activities they will perform and making necessary arrangements in the teaching process.

The subjective beliefs of individuals about knowing what knowledge is and how learning process occurs are generally expressed as epistemological beliefs. Epistemological beliefs are defined as "what is knowledge?", "how to acquire knowledge?", "what is the degree of certainty of information?", "what are the limits and criteria for information?" by different authors (Özden, 2003: 6, Hofer and Pintrich, 1997: 88). The epistemological development of individuals in such a process has been examined by Perry (1970). Perry (Akt, Thomas, 2008) studied changes in university students' beliefs about information at Harvard University in the Scheme of Intellectual and Ethical Development; and determined that students come to the university by believing that information is something that is absolute and definite (either right or wrong), simple, easy to understand and structured by an expert and passed on to the students, however in following years they believe that information cannot be absolute and definite but it has a multifaceted structure consisting of many interrelated parts. According to Perry's model, in terms of epistemological development levels, individuals go through some developmental processes as; 1) dualist position in which they adopt the belief of that information is either true or false and only experts have correct knowledge, 2) multiplicity position in 
which first they start to understand that information is not definite and absolute but partly they believe in that there is a knowable unchanging reality in the external world and then they comprehend that even an expert's knowledge may not be accurate and everyone has the right to build an opinion, 3) relativist position in which they accept that information can be either right or wrong only according to available context and they start to see themselves as real meaning-makers, 4) with the acceptance of relativity of information, commitment position in which they firmly believe in a specific opinion or a perspective responsively. Shommer (1990) pointed out that the treatment of epistemological beliefs in a way that only covers beliefs related to knowledge is a limited approach, and that these beliefs do not have a one-dimensional structure but a multidimensional one, and she had mooted that epistemological beliefs also include the beliefs related to the learning and teaching ability (intelligence) with respect to knowledge acquisition and usage of it, therefore they should be regarded as a belief system, too (Schommer, Mau, Broohart and Hutter, 2000, Deryakulu, 2004). However, those who have a "multidimensional" perspective accept that the reality is not certain and can change and that knowledge cannot be "given" but it can be structured. Epistemological beliefs cover different dimensions about certifying knowledge claims, in other words, they are related to all possibilities of knowledge (Pieschl, Staahl and Bromme, 2008). When we review the literature, we see studies pointing that epistemological beliefs are correlated with variables such as school success (Buehl and Alexander, 2005), learning and teaching approaches (Kizllgunes, Tekkaya and Sungur, 2009; Sinatra and Kardash, 2004), learning styles (Demir and Bal, 2014), motivation and learning (Buehl and Alexander, 2005), learning style and reflective thinking (Phan, 2008). Deryakulu (2004) studied the relationship between learning and studying strategies and epistemological beliefs of students in their work. The result of the study shows that the BLDE from the epistemological beliefs is a significant predictor of attitude, motivation, concentration, information processing, selecting main ideas, study assistants, self-testing and test strategies for learning and teaching strategies. In addition, BLDA is an important predictor of attitude, motivation, time use, anxiety, concentration, selecting main ideas, and test strategies, while BOOT is a predictor of motivation, anxiety, study assistants, self-testing, and test strategies. The study by Terzi (2005) aims to determine the scientific epistemological beliefs of university students. The research result reveals that the students have a positivist understanding of science. It also shows that students studying social sciences are more positivist than students studying science, also female students are more positivist than males. In a study to determine the epistemological beliefs of teacher-to-be students (Aypay, 2009), it has been determined that Turkish teacher-to-be students tend to believe that the process of knowledge acquisition is important for learning, that expert knowledge should be questioned, and that effort is important to learn. Hacıömeroğlu (2011) studied the epistemological beliefs of primary school teacher candidates to predict their mathematical problem-solving beliefs. The result also has shown that epistemological beliefs play an important role in predicting beliefs about problem-solving and that there is a relation between mathematical problem-solving beliefs and epistemological beliefs of primary school teacher candidates. However, Taşkın (2012) examined epistemological beliefs as a predictor of primary school teacher candidates' learning attitudes. The study findings indicate that BLDE from the epistemological beliefs of the teacher candidates is significantly related to the Deep Learning approach and that BOOT is a significant predictor of the Superficial Learning approach. As a result of the research of Demir (2012), the epistemological beliefs of primary school teacher candidates are found to be medium-level. Moreover, it has been found out that the epistemological beliefs of the teacher candidates who take the course of Scientific Research Methods are significantly higher than those who have not taken the course yet. Similarly, Sapanca (2012) examined the relationship between the teacher candidates' epistemological beliefs, their metacognition levels, and their academic achievement and observed a positive correlation. Basbay's study (2013) suggests that students' critical thinking tendencies will affect epistemological beliefs and that metacognition has a partial mediator effect in this relation. In the study conducted with a total of 425 students studying at various faculties and departments of Ege University, it has been found that the metacognitive variable is a partial mediator variable in the model which the critical thinking tendencies affect epistemological beliefs. Likewise, Yilmaz-Tüzün and Topçu (2013) studied the epistemological beliefs, epistemological worldviews and self-efficacy beliefs of science teacher candidates in terms of their academic achievement and gender. The study was conducted with 391 prospective teachers.

In addition to epistemological belief factors, the epistemological worldview and self-efficacy belief have been explored to understand how they affect academic achievement. In the conclusion of the study, innate ability, lack of information complexity, and epistemological worldview could explain the academic success of participants in a statistically significant manner. In addition to this, differences were found in innate ability, knowledge being determined by the authority, and self-efficacy beliefs in both dimensions in terms of gender for final year students. The study that Bedel and Çakır (2013) conducted also examined the relationship between preschool and biology teacher candidates' cognitive awareness and epistemological beliefs. It revealed that there is a difference only in the sub-dimension of beliefs about superstitious rituals among pre-school and biology teacher 
candidates about epistemological beliefs. Durdukoca (2016) examined the influence of the systematic education model on learners' epistemological beliefs, learning approaches, metacognitive awareness, and academic achievement. Teacher candidates in the experimental group in which the systematic education model was applied in the research; in terms of epistemological belief, BLDA and BOOT are less developed than the control group in which the traditional education model was applied. Türkan, Aydın and Üner (2016) examined the relationship between the teacher candidates' multicultural attitudes and their epistemological beliefs. Findings from the research show that as teachers' attitudes for multicultural education increase, also their belief in the structuring of knowledge increases.

There are studies about the determination of epistemological beliefs in foreign literature. One of these studies, Chan and Eliot Epistemological Beliefs Questionnaire is the adaptation of "Epistemological Beliefs Questionnaire" by Schommer (1990) with 63 items. The researchers created a new scale form by subjecting Schommer's original scale to factor analysis once again. For this purpose, Schommer's original 63-item scale was translated into Chinese and a linguistic equivalence study was conducted. Factor analysis showed that the factor structures that Schommer identified in his study did not appear in this study (Chan and Eliot, 2000, 2004). The researchers then prepared a new 45 -item draft form by taking earlier criticism on Schommer's scale into consideration and adding new items, they applied it to 385 teacher candidates from Hong Kong and developed a 30 -item scale. This 30 -item scale provided a four-factor structure. Alpha coefficients range from .60 to .70 for the scale reliability.

Looking at the domestic literature, there are scale development and adaptation studies to measure epistemological beliefs. The Epistemological Beliefs Scale developed by Schommer (1990) was adapted to Turkish by Büyüköztürk and Deryakulu (2002) to determine the epistemological beliefs of the students. The original scale had a test-retest reliability of .74, and the Cronbach's alpha internal consistency coefficients of the factors ranged from .83 to .59 . As a result of the factor analysis conducted by Büyüköztürk and Deryakulu (2002), it was seen that the Epistemological Beliefs Scale showed a very different three-factor structure on the Turkish university students and it was composed of 35 items. There are 18 items in the first factor named BLDE. This is an example of a substance contained in this factor; "If someone does not understand something, they must continue to try to understand it.". There are 8 items in the third factor named BLDA. The Cronbach's alpha internal consistency coefficients calculated depending on item analysis of the scale were found to be .83 for factor $1, .62$ for factor $2, .59$ for factor 3 , and .71 for the whole scale.

Oksal, Şenşekerci, and Bilgin (2006) developed a tool to measure the central epistemological beliefs that constitute the basis for the beliefs of teacher candidates about learning-teaching processes. A five-point Likert-type scale consisting of 23 items considered to represent central epistemological beliefs was obtained. In order to determine the validity of the structure of the scale, the factor structure of the collected data which is gathered from 350 teacher candidates was examined through the Principal Component Analysis method. When the items of the factors are examined, subscales are named as that the first factor is "Belief in science as a source of information", the second factor is "Belief in a rational community", the third factor is "Belief in superstitious rituals" and the fourth factor is "Belief in supernatural powers". The alpha reliability coefficients of the subscales are calculated as .85 for "Belief in science as a source of information", .77 for "Belief in a rational community", .75 for "Belief in superstitious rituals" and .66 for "Belief in supernatural powers".

Çoban and Ergin (2008) aimed to develop a valid and reliable scale in order to determine the opinions of primary school students about scientific knowledge. A total of 505 students participated in the research from 6th, 7th and 8th grades of 7 primary schools. At the end of scale development studies, it was identified that the scale was composed of totally 16 items with three factors namely, scientific knowledge is closed (8 items), scientific knowledge is justified (5 items) and scientific knowledge may change (3 items) and the whole scale's Cronbach reliability coefficient was 0.83 .

Another is Epistemological Beliefs Questionnaire (EBQ) adapted by Aypay (2009) from Chan and Elliot (2002, 2004). For this purpose, the scale consisting of 30 items was translated into Turkish by the researcher. This scale was applied to 341 students in total consisting of ÇOMU Faculty of Education students and ÇOMU Institute of Social Sciences non-thesis master's degree students. According to the Confirmatory Factor Analysis result, the scale shows a structure of four factors (Learning Process Suspicion of Authority/Expert Knowledge, Innate/Fixed Ability, Learning Effort, and Certainty of Knowledge) which express four dimensions of belief. This accounts for $37.18 \%$ of the total variance. The RMSEA value in the analysis results was found to be .054, (NFI) 0.64, (CFI) 0.77. The calculated Alpha coefficient for the whole scale is .78 while the Alpha coefficients for the four sub-factors are $.77, .74, .59$ and .52 respectively.

Moreover, the Scientific Epistemological Beliefs Scale developed by Elder (1999) in order to measure the beliefs of elementary school students about scientific knowledge was adapted to Turkish culture by Acat, Tüken and Montenegro (2010). The study was carried out with a sample group of 212 students studying in the primary schools in Bozüyük, Bilecik province. It was determined that the correlation coefficients obtained from total and residue item correlations of the scale were above 0.08 . As a 
result of descriptive factor analysis; the scale is a sum of five (5) subscales, namely, (i) Authority and Accuracy, (ii) Knowledge Generation Process, (iii) Source of Knowledge, (iv) Reasoning and (v) Variation of Knowledge. The eigenvalue of the scale at 5 factors is 13.193 and the percentage of variance is 52.77 . Factor load values of the scale items range between 0.49 and 0.76 . The Cronbach Alpha coefficient was found to be 0.57 to 0.86 for the subscales and 0.82 for the whole scale.

Ekici and Kaya (2016) are not satisfied with only one scale so they used two different thematic scales as a base for the research with the subject of "Social Science Teachers' Relationship between Teaching Styles and Epistemological Beliefs". First of all, they adapt the "Epistemological Belief Scale" of Schommer (1990) which has been translated into Turkish, and also its validity and reliability study is performed by Deryakulu and Büyüköztürk (2002) for epistemological beliefs. Since the information of the same person is stated above, it is not mentioned here in order not to fall back. In the determination of instructional styles, "Instructional Style Scale" is used, that is developed by Grasha (1996) who also done its reliability and validity studies. As a result of the scale, it is stated that the teachers will be divided into four groups according to the scores they receive on the scale and that they do not have the single teaching style. In the research done by Ekici and Kaya (2016), findings overlap with findings of the first practitioner of the scale. It has been determined that Social Sciences teachers collect more than one teaching style in their structure. However, their most preferred group of instructional styles was recorded as Facilitator/Personal Model/Expert with a percentage of $50 \%$.

The study entitled "Analysis of the Epistemological Beliefs of Social Science Teacher Candidates" penned by Içen, İlgan and Göker (2013) is also found to be an essential element for researchers because the adapted scale letter is not performed literally and has been subjected to a validation-reliability study anew. The basis of the research is the Epistemological Belief Scale, which is adapted by Karhan (2007) in Turkey. The Epistemological Belief Scale developed by Schommer (1998) is a 5-point Likert-type scale and propositions in the scale are expressions that are shared by individuals with superficial epistemological beliefs. In the adaptation study conducted by Karhan (2007), it was determined that the scale had a three-factor structure as a result of exploratory factor analysis. The first factor is named as "experts are the source of knowledge and learning depends on ability". This factor included 17 items (m1-m17). The second factor is named "learning does not depend on effort". Eleven items (M18-m28) are present in this dimension. The third dimension is called "information is unique and the absolute", and 10 items exist in this dimension. The reliability alpha value is 72 for the first factor, which consists of 17 items, 16 of them is negative, 1 positive; 68 for the second factor of 11 items; 67 for the third factor consisting of 10 items and again 67 for the whole scale.

However, the epistemological beliefs of teachers influence the way they conceptualize teaching (Chan and Elliott, 2004). Therefore, in order to improve teachers' competence and proficiency, the determination of their beliefs about science emerges as an important variable. In this study, the Epistemological Beliefs Scale (EBS) is developed to measure the students' perceptions of science in their lives. Accordingly, maturing the beliefs on the science of the Faculty of Education students is closely related to the development of the epistemological beliefs of individuals. Individuals who are aware of their own mature epistemological beliefs and who develop these skills will be able to take responsibility for themselves in the learning process and will be able to experience the sense of self actively with the help of personal responsibilities. From this point of view, the general purpose of the research is to determine the level of epistemological beliefs of teacher candidates at the level of education faculty and to develop a measurement instrument to be used in the determination.

\section{Method}

\subsection{Model of the Research}

The study is a research conducted by improving the "Epistemological Beliefs Scale" (EBS) at the level of education faculty and operating validity and reliability studies. In the process of developing the measurement instrument, a path is followed in order of constructing scale items, receiving expert opinion for scope validation, trial application, and in the analysis of data Exploratory Factor Analysis, Confirmatory Factor Analysis (CFA) and validity reliability study.

\subsection{Population and Sample}

\subsubsection{Population and Sample Features}

The teacher candidates who study in the social science department of the Faculty of Education in Kafkas University during the 2013-2014 school year constitute the population of the study. The sample of 176 students is obtained from 4 classes $\left(1^{\text {st }}, 2^{\text {nd }}, 3^{\text {rd }}\right.$ and $\left.4^{\text {th }}\right)$ decided with nonprobabilistic cluster sampling method, $111(63,1 \%)$ of students are from daytime education, 52 (29,5\%) from evening education, $13(7,4 \%)$ are unspecified. $68(38,6 \%)$ of the students specify their gender as female and 104 $(59,1 \%)$ of them as male, while $4(2,3 \%)$ of them do not specify a gender at all. $36(20,5 \%)$ of the students are in the $1^{\text {st }}$ grade, $28(15,9 \%)$ of them in the $2^{\text {nd }}$ grade, $51(29 \%)$ in the $3^{\text {rd }}$ grade and $58(33 \%)$ of them in the $4^{\text {th }}$ grade according to grade variable. 


\subsection{Preparation Process of the Epistemological Beliefs Scale}

The following steps suggested by De Vellis (2003) are followed in the process of preparing the Epistemological Beliefs Scale (EBS).

Preparation of the item pool: The EBS development process starts with studies preparing the item pool. Hence, first, the relevant literature is searched and data is examined to decide what characteristics these practices should have in order to develop epistemological beliefs in teacher candidates. First drafts are written in line with these determinations. The drafts are written within the concept of "advanced epistemological beliefs" that are operationally defined to encompass developmental dimensions of learning behaviors and application environment for epistemological beliefs. These prepared items are carefully re-examined and a pool of 100 items is created.

Expert opinions about the item pool: The item pool has been delivered to a total of three specialists for expert opinions. One of these specialists is an individual who has taken a course of thinking education in the context of a graduate program; another one is an instructor who has worked in the Department of Educational Sciences at the Faculty of Education of Çukurova University and has lectured a scientific research course and specialized in the learning-teaching process. The other specialist is also an instructor who works in Adnan Menderes University, Faculty of Education, Department of Educational Sciences, and lectures scientific research course and is an expert on the learning-teaching process.

\subsection{Analysis of Data}

Cronbach Alpha analysis for reliability, expert opinions for scope validity, explanatory and confirmatory factor analysis for construct validity are conducted on the collected data within the scope of EBS's validity and reliability analyses. In addition, the arithmetic average and standard deviation values and item-total score correlations of the items are examined and the item discrimination index is calculated by t-test analysis. Arithmetic average, t-test, and one-way variance analysis techniques are used to compare the data in terms of gender, type of education and class variables.

\section{Findings}

\subsection{Findings of the Structural Validity and Safety Study of EBS}

Accordingly, prepared 50-item tentative scale is checked for language and clarity by applying it to a group of 30 people consisting of students from social sciences teaching department. In line with the suggestions made, necessary arrangements on items are made in terms of expression and page layout. The 44-item tentative scale form has been finalized as a result of these studies and applied to 176 education faculty students from four grades in a single session in the classroom environment. The results of the Barlett Sphericity test and the Kaiser-Meyer-Olkin (KMO) coefficient are examined to determine whether the data is appropriate for factor analysis at the beginning of the factor analysis conducted to identify the factor structure of EBS, and the values are found to be statistically significant $\left(\mathrm{KMO}=0.784\right.$, Barlett Sphericity test $\chi^{2}=610.108 \mathrm{df}=$ $105 p<.001)$. As a result of the application of EBS with 176 students, Cronbach Alfa reliability value is .71 in total for the three-dimensional 15 -item form, .78 for the first sub-factor (BLDE) (7 items), .69 for the second sub-factor (BLDA) (4 items), .51 for the third sub-factor (BOOT) (4 items).

Factors, factor loadings, factor eigenvalues, variance percentages and Cronbach Alpha values that are gathered from the security and factor analyses that are obtained after ten iterations and concluded with a three-factor structure; adjusted total item score correlations (r), common variances and $t$ values are shown in Table 1 . 
Table 1. Factors, Factor Loads, Variance Percentages Expressed by Factors, and Total Item Correlation Values (r) of Epistemological Beliefs Scale

\begin{tabular}{|c|c|c|c|c|c|c|c|}
\hline Item No & $\mathrm{F} 1$ & $\mathrm{~F} 2$ & F3 & $\bar{x}$ & $\mathrm{~T}$ & SS & $\mathrm{r}$ \\
\hline 34 &, 73 & & & 4,53 & 3.74 &, 57 & $27 *$ \\
\hline 3 &, 72 & & & 4,47 & 5.28 &, 57 &, $32 *$ \\
\hline 7 & ,68 & & & 4,52 & 4.77 &, 53 & ,28* \\
\hline 16 & ,65 & & & 4,61 & 5.92 &, 54 &, $41^{*}$ \\
\hline 37 & ,60 & & & 4,42 & 8.01 & ,61 &, $50 *$ \\
\hline 31 &, 57 & & & 4,19 & 5.12 & ,63 & ,39* \\
\hline 13 &, 50 & & & 4,14 & 6.37 & ,68 &, $35^{*}$ \\
\hline 32 & &, 81 & & 2,59 & 6.29 & 1,20 &, $30 *$ \\
\hline 29 & &, 78 & & 2,37 & 5.95 & 1,08 &, $28 *$ \\
\hline 23 & &, 71 & & 2,53 & 7.32 & 1,25 &, $36^{*}$ \\
\hline 35 & &, 52 & & 2,77 & 5.57 & 1,15 &, $27 *$ \\
\hline 44 & & & ,69 & 3,73 & 6.40 & ,98 &, $27 *$ \\
\hline 4 & & & ,61 & 4,24 & 5.17 & ,73 &, $34^{*}$ \\
\hline 42 & & &, 59 & 3,70 & 5.79 & ,90 &, $31^{*}$ \\
\hline 15 & & & ,46 & 4,00 & 7.09 &, 80 &, $38 *$ \\
\hline \multirow[t]{2}{*}{ Range } & $.50-.73$ & $.52-.81$ & $.46-.69$ & $2.37-4.61$ & $3.74-8.01$ & $.53-1.25$ & $.27-.50$ \\
\hline & & & & & & & Total \\
\hline Variance \% & 25,264 & 15,110 & 7,409 & & & & 47,783 \\
\hline Cronbach Alpha & .786 & .693 & .515 & & & & .715 \\
\hline
\end{tabular}

R: total item correlations; * means "Significant at .05 level". Note: For ease of monitoring, factor loads less than .30 are not shown in the table. F1: The belief that learning depends on effort (BLDE); F2: Belief that learning depends on ability (BLDA); F3: Belief that there is only one truth (BOOT)

Factor structure of EBS is investigated using exploratory factor analysis (EFA) and confirmatory factor analysis (CFA). The exploratory factor analysis aims to explore factor structure based on the relationships between variables. The confirmatory factor analysis, which examines model-data compatibility, tests established hypotheses about the relationship between variables (Tabachnick and Fidell, 2001).

The first component obtained as a result of the analyses is the dimension of BLDE which consists of 34th, 3rd, 7th, 16th, 37th, 31st and 13th items that are the relevant expressions required for evaluation. Some of the items on this scale are; "Students must continue to make efforts to ensure permanent learning", "It is necessary to make different efforts when solving the problems encountered in the present life". The factor loadings of 7 items in this subscale are between .50-.73; total item correlations are between .27 and .50 and the Cronbach Alfa internal consistency coefficient is .786. According to the results of the exploratory factor analysis, the second component of the EBS consists of four components (Item poll no: 32, 29, 23 and 35) related to its dimension, such as "Some are innate good students and they are successful for lifelong" and "Integrating newly learned information with previously learned information is a confusing process". Factor loadings of the items in this factor called "Belief that learning depends on ability" are between .52-.81; total item correlations are between .27 and .36 , while the Cronbach
Alpha internal consistency coefficient is .693. The third factor from the EBS analysis results is composed of four items in the form of expressions such as "The most important part of scientific studies is cognitive flexibility" which deals with the dimension of epistemological beliefs of the students in the education faculty. This factor is called "Belief that there is only one truth" (BOOT). The factor loadings of these sub-items (Item no: 44, 4, 42 and 15), which have a Cronbach Alpha internal consistency coefficient of .515 , are between .46 and .69 , while total item correlations are between .27 and .38 .

The three subscales account for $47.783 \%$ of the total variance. The Cronbach Alpha internal consistency coefficient for the complete scale is .715. The Guttman Split Half values, calculated with the half test technique to get an idea of the consistency of the scale or the consistency between the two halves, are .74 for the BLDE subscale, .78 for the BLDA subscale, and .45 for the BOOT subscale and .64 for the whole scale. When Table 1 is examined in terms of factor loadings, it shows that there is a change in factor loadings. When we look at the items loaded on multiple factors, it is seen that the items are generally loaded into the relevant subscales with significant differences (usually around .30 and above). Moreover, the total scores of 15 items reached by the individuals whom the data is collected are ranked separately from lowest to highest for each item, and lower $27 \%$ and upper $27 \%$ groups are formed and it is 
investigated whether or not the items distinguish between these two groups. As a result of this examination, it is seen that all the items are able to distinguish groups significantly $(\mathrm{p}<.001)$. The arithmetic averages of the remaining 15 items ranged from 2.37 to 4.61 , and the standard deviations ranged from .53 to 1.25 .

The confirmatory factor analysis is used to test the accuracy of the identified three-factor structure. Although there are many statistics for data compatibility of the model, generally addressed indicators are $\chi^{2}, \chi^{2} / \mathrm{df}$, RMSEA, NNF, the CFI and GFI values (Sümer, 2000; Çokluk, Büyüköztürk and Şekercioğlu, 2010). The chi-square value calculated for model-data alignment and the confirmatory factor analysis conducted to investigate goodness of fit of collected data and the EBS's three-factor model is found significant $\left(\chi^{2}=122.03 \mathrm{~K}, \mathrm{df}=87, \mathrm{p}<.01\right)$. When examining the tested three-factor model after conducting CFA, it is seen that values of the fit indices meet suggested criteria with $\mathrm{RMSEA}=0.048$ and $\chi^{2} / \mathrm{df}=1.402$ and RMR $=0.055, \quad$ STRMR $=0.066, \quad$ GFI $=0.91, \quad$ AGFI $=0.88$, $\mathrm{NFI}=0.81, \quad \mathrm{NNFI}=0.92, \quad \mathrm{CFI}=0.93, \quad \mathrm{IFI}=0.93 . \quad$ The standardized coefficients showing the relationship between the items and related factors exchange and all of them are significant at .01 level. Generally, when the model fit indices are examined, a moderate level of coherence is observed but the model with RMSEA $=0.048, \chi^{2} / \mathrm{df}=$ 1,402 (Tabachnick and Fidelle, 2001; Akt; Çokluk et al, 2010, 271) performs a perfect fit.

\subsection{BLDE, BLDA and BOOT Analysis of EBS in Terms of Class Level, Type of Instruction and Gender}

Table 2 contains the results of one-way analysis of variance related to significant differences in the dimensions of BLDE, BLDA, and BOOT of EBS in terms of class.

As seen in Table 2, there is not a significant difference in the dimensions of BLDE $[F(3,172)=2,406 ; p>.05]$ and BOOT $[F(3,172)=.883 ; p>.05]$ of EBS in terms of class level. However, BLDA $[F(3,172)=2.718 ; \mathrm{p}<.05]$ and total $[F(3,172)=3.923 ; p<.05]$ show a significant difference.

According to the results of the Scheffe test conducted to find out which groups differ according to the class level, it is seen that the first grade average $(=59,36)$ in the total dimension is higher than the other group averages.

Table 2. ANOVA Results of EBS in terms of Class Level

\begin{tabular}{|c|c|c|c|c|c|c|c|c|c|}
\hline Dimensions of Epistemological Beliefs & Class Level & $\mathrm{N}$ & $\bar{x}$ & SS & Sum of Squares & sd & Avg. of Squares & $\mathrm{F}$ & $\mathrm{p}$ \\
\hline \multirow{5}{*}{ BLDE } & First & 36 & 31,95 & 2,90 & \multirow{5}{*}{$\begin{array}{c}52,799 \\
1236,399 \\
1289,197\end{array}$} & \multirow{5}{*}{$\begin{array}{c}3 \\
169 \\
172\end{array}$} & \multirow{5}{*}{$\begin{array}{r}17,600 \\
7,316\end{array}$} & \multirow{6}{*}{2,406} & \multirow{6}{*}{, 069} \\
\hline & Second & 28 & 30,90 & 2,29 & & & & & \\
\hline & Third & 50 & 30,43 & 2,44 & & & & & \\
\hline & Fourth & 59 & 30,72 & 2,95 & & & & & \\
\hline & Total & 173 & 30,92 & 2,73 & & & & & \\
\hline \multirow{5}{*}{ BLDA } & First & 36 & 11,55 & 4,18 & \multirow{5}{*}{$\begin{array}{c}88,981 \\
1844,324 \\
1933,305\end{array}$} & \multirow{5}{*}{$\begin{array}{c}3 \\
169 \\
172\end{array}$} & \multirow{5}{*}{$\begin{array}{l}29,660 \\
10,913\end{array}$} & & \\
\hline & Second & 28 & 10,28 & 2,65 & & & & \multirow{4}{*}{2,718} & \multirow{4}{*}{, 046} \\
\hline & Third & 50 & 9,74 & 2,93 & & & & & \\
\hline & Fourth & 59 & 9,74 & 3,26 & & & & & \\
\hline & Total & 173 & 10,20 & 3,35 & & & & & \\
\hline \multirow{5}{*}{ BOOT } & First & 36 & 15,84 & 2,00 & \multirow{5}{*}{$\begin{array}{c}12,413 \\
792,217 \\
804,630\end{array}$} & \multirow{5}{*}{$\begin{array}{c}3 \\
169 \\
172\end{array}$} & \multirow{5}{*}{$\begin{array}{l}4,138 \\
4,688\end{array}$} & \multirow{5}{*}{, 883} & \multirow{5}{*}{, 451} \\
\hline & Second & 28 & 15,91 & 1,95 & & & & & \\
\hline & Third & 50 & 15,22 & 2,44 & & & & & \\
\hline & Fourth & 59 & 15,70 & 2,09 & & & & & \\
\hline & Total & 173 & 15,63 & 2,16 & & & & & \\
\hline \multirow{5}{*}{ Total } & First & 36 & 59,36 & 6,30 & \multirow{5}{*}{$\begin{array}{c}359,063 \\
5156,220 \\
5515,283\end{array}$} & & \multirow{5}{*}{$\begin{array}{c}119,688 \\
30,510\end{array}$} & \multirow{5}{*}{3,923} & \multirow{5}{*}{,010 } \\
\hline & Second & 28 & 57,09 & 5,43 & & & & & \\
\hline & Third & 50 & 55,40 & 5,53 & & 169 & & & \\
\hline & Fourth & 59 & 56,18 & 5,02 & & 172 & & & \\
\hline & Total & 173 & 56,76 & 5,66 & & & & & \\
\hline
\end{tabular}


Table 3 contains the t-test results related to whether or not they show a significant difference in terms of education type of the dimensions of BLDE, BLDA and BOOT of EBS.

Table 3. T-test Results of EBS in terms of Education Type

\begin{tabular}{|c|c|c|c|c|c|c|c|}
\hline Dimensions of Epistemological Beliefs & Education Type & $\mathrm{N}$ & $\bar{x}$ & $\mathrm{~s}$ & $\mathrm{sd}$ & $\mathrm{t}$ & $\mathrm{p}$ \\
\hline \multirow{2}{*}{ BLDE } & Daytime Education & 111 & 31,13 & 2,72 & \multirow[t]{2}{*}{161} & \multirow[t]{2}{*}{1,597} & \multirow{2}{*}{.112} \\
\hline & Evening Education & 52 & 30,38 & 2,94 & & & \\
\hline \multirow{2}{*}{ BLDA } & Daytime Education & 111 & 10,51 & 3,71 & \multirow[t]{2}{*}{161} & \multirow[t]{2}{*}{1,169} & \multirow{2}{*}{.24} \\
\hline & Evening Education & 52 & 9,84 & 2,80 & & & \\
\hline \multirow{2}{*}{ BOOT } & Daytime Education & 111 & 15,76 & 2,19 & & \multirow{2}{*}{.540} & \multirow{2}{*}{.590} \\
\hline & Evening Education & 52 & 15,56 & 2,29 & 161 & & \\
\hline \multirow{2}{*}{ Total } & Daytime Education & 111 & 57,42 & 6,11 & 161 & \multirow{2}{*}{1.665} & \multirow{2}{*}{.098} \\
\hline & Evening Education & 52 & 55,79 & 5,15 & & & \\
\hline
\end{tabular}

When Table 3 is examined, the level of epistemological beliefs that students perceive does not differ significantly in terms of education types; BLDE [t $(161)=1.597 ; \mathrm{p}>.01]$, BLDA [t $(161)=1.169 ; \mathrm{p}>.01]$, BOOT [t $(169)=540 ; \mathrm{p}>.01]$ and total $[\mathrm{t}(161)=1.665 ; \mathrm{p}>.01]$.

Table 4 shows the t-test results related to whether or not they differ significantly of dimensions of BLDE, BLDA, BOOT of EBS in terms of gender type.

Table 4. T-test results of EBS in terms of gender

\begin{tabular}{|c|c|c|c|c|c|c|c|}
\hline Dimensions of EBS & Gender & $\mathrm{N}$ & $\bar{x}$ & $\mathrm{~S}$ & $\mathrm{sd}$ & $\mathrm{t}$ & $\mathrm{p}$ \\
\hline \multirow{2}{*}{ BLDE } & Female & 68 & 31,25 & 2,53 & \multirow{2}{*}{170} & \multirow{2}{*}{1.271} & \multirow{2}{*}{.206} \\
\hline & Male & 104 & 30,70 & 2,91 & & & \\
\hline \multirow{2}{*}{ BLDA } & Female & 68 & 9,84 & 3,00 & \multirow{2}{*}{170} & \multirow{2}{*}{-1.252} & \multirow{2}{*}{.212} \\
\hline & Male & 104 & 10,51 & 3,65 & & & \\
\hline \multirow{2}{*}{ BOOT } & Female & 68 & 15,45 & 2,20 & \multirow{2}{*}{170} & \multirow{2}{*}{-1.128} & \multirow{2}{*}{.261} \\
\hline & Male & 104 & 15,83 & 2,21 & & & \\
\hline \multirow{2}{*}{ Total } & Female & 68 & 56,55 & 5,79 & \multirow{2}{*}{170} & \multirow{2}{*}{.-559} & \multirow{2}{*}{.577} \\
\hline & Male & 104 & 57,06 & 5,80 & & & \\
\hline
\end{tabular}

When Table 4 is examined, the level of epistemological beliefs that students perceive does not differ significantly in terms of gender BLDE $[\mathrm{t}(170)=1.271 ; \mathrm{p}>.01]$, BLDA $[\mathrm{t}(170)=-1.252 ; \mathrm{p}>.01]$, BOOT $[\mathrm{t}(170)=-1.128 ; \mathrm{p}>.01]$ and total $[\mathrm{t}(170)=-559 ; \mathrm{p}>.01]$.

\section{Discussion, Result and Suggestions}

Epistemological beliefs are the patterns that individuals use in developing and maturing science and scientific knowledge. In such a process, determining the beliefs that teachers have about the nature of science and the creation and development of scientific knowledge will contribute to increasing the quality of instructional design they will create with their students. In the preparation of teaching environments, teachers who realize that effort is necessary for learning process will reflect this awareness to their students and thus contribute to the development of independent learners.

Within the scope of this research, reliability and validity study of The Epistemological Beliefs Scale which is developed by Kop and Demir (2014) is conducted. In the process of determining the epistemological beliefs of teacher candidates, many fit indexes are used such as Chi-Square Goodness of Fit Test $\left(\chi^{2}\right)$, Goodness of Fit
Index (GFI) Adjusted Goodness of Fit (AGF), the Comparative Fit Index (CFI), Normed Fit Index (NFI), Non-Normed Fit Index (NNFI) and the Root Mean Square Error of Approximation (RMSEA) (Simsek, 2007). As a result of exploratory factor analysis, Kaiser-Meyer-Olkin (KMO) coefficient and Barlett Sphericity test results are examined in the study and these values are found to be statistically significant $(\mathrm{KMO}=0.784$; Barlett Sphericity test $\left.\chi^{2}=610.108 \mathrm{df}=105 \mathrm{p}<.001\right)$. Epistemological beliefs scale consists of three subscales and these three subscales explain $47.783 \%$ of the total variance. The Cronbach Alpha internal consistency coefficient for the complete scale is .715. The Guttman Split Half values that are computed by splitting the test in half with the aim of getting an idea about the scale stability or consistency of its two halves are .74 for the BLDE subscale, .78 for the BLDA subscale, .45 for the BOOT subscale and .64 for the whole scale. Thus, a reliable 15-item measuring instrument has been obtained. 
Moreover, there seems to be no significant difference in the BLDE and the BOOT dimensions of the EBS of students in terms of class level. However, there is a significant difference in the BLDA dimension. This result can be interpreted as the fact that teacher candidates' opinions on their ability to contribute to the learning process are more intense in the first grade. Likewise, it seems that BLDA, BLDE, BOOT and all together do not differ significantly in terms of education type and gender.

Providing a reliable and valid measuring instrument that will determine the epistemological beliefs of prospective teachers will contribute to future experimental and operational research. In addition, identifying epistemological beliefs of teacher candidates will also contribute to developing a process in which science and knowledge are welcomed. Furthermore, teachers who are aware of their own scientific knowledge beliefs will be able to realize their deficiency or their proficiency and so they will be able to give feedback on their own in this direction and this process will ultimately be accompanied by the development of their competence. Therefore, students of a teacher who is open to scientific knowledge will also be open to scientific knowledge and take place in the process of advanced epistemological beliefs.

\section{REFERENCES}

[1] Acat, M. B., Tüken, G., \& Karadağ, E. (2010). Scientific epistemological beliefs scale: Adjusting for Turkish culture, language validity, and factor structure examination. Journal of Turkis Science Education, 7(4), 67-89.

[2] Aypay, A. (2009). Epistemological beliefs about the learning and teaching of teacher candidates. In "The VIII. National Primary School Teaching Symposium" (pp. 540-550). Eskisehir: Eskisehir Osmangazi University

[3] Aypay, A. (2011). Adjusting the epistemological beliefs scale for Turkey and examination of epistemological beliefs of teacher candidates. Eskisehir Osmangazi University Social Sciences Journal, 12 (1).

[4] Başbay, M. (2013). Examination of the relationship between epistemological belief and critical thinking and metacognition by structural equality model. Education and Science, 38 (169).

[5] Bedel, E. F., \& Cakir, M. (2013). Examination of metacognitive awareness and epistemological beliefs in preschool and biology teacher candidates.

[6] Buehl, M. M., \& Alexander, P. A. (2005). Motivation and performance differences in students' domain-specific epistemological belief profiles. American Educational Research Journal, 42 (4), 697-726.

[7] Chan, K. W., \& Elliott, R. G. (2002). Exploratory study of Hong Kong teacher education students' epistemological beliefs: Cultural perspectives and implications on beliefs research. Contemporary Educational Psychology, 27, $392-414$.
[8] Coban, G. Ü., \& Ergin, Ö. (2008). Scale for determining the opinions of elementary school students about scientific knowledge. Elementary online, 7 (3).

[9] Çokluk, Ö., Șekercioğlu, G. and Büyüköztürk, Ș. (2010). Multivariate Statistics for Social Sciences: SPSS and LISREL Applications. Pegem Academy. Ankara.

[10] Demir, M. K. (2012). Examination of epistemological beliefs of elementary school teacher candidates. Uluda $\breve{g}$ University Journal of Faculty of Education, 25 (2).

[11] Demir, Ö. and Bal, A., P. (2014). An examination of epistemological beliefs and learning styles of students of science and technology and primary school teaching. Electronic Journal of Educational Sciences, 3 (5), 12-30.

[12] Deryakulu, D. (2004), Epistemological Beliefs, Y. Ruzgun and D. Deryakulu (Editor), Individual Differences in Education, ss. 259-289, Ankara: Nobel Publication.

[13] Deryakulu, D. (2004). The relationships between university students' learning and study strategies and their epistemological beliefs. Educational Administration in Theory \& Practice, 38, 230-249.

[14] Deryakulu, D. ve Büyüköztürk Ş. (2002), Validity and Reliability Study of Epistemological Belief Scale. Journal of Educational Researches, 2(8), ss. 111- 125.

[15] Durdukoca, Ş. F. (2016). The effect of systematic education on learners' epistemological beliefs, learning approaches, metacognitive awareness and academic achievement. Journal of Human Sciences, 13(2), 3073-3091.

[16] Ekici, M. ve Kaya, E. (2016). The Relation Between Epistemological Beliefs And Teaching Styles Of Social Sciences Teachers, Route Educational and Social Science Journal Volume 3(1), 195-218.

[17] Grasha, A. F. (1996). Teaching with Style: A Practical Guide to Enhancing Learning by Understanding Teaching \& Learning Styles. Pittsburgh, PA: Alliance Publishers United States of America.

[18] Haciömeroğlu, G. (2011). An Examination of Epistemological Beliefs to Predict Their Beliefs on Mathematical Problem Solving of Primary School Teacher Candidates. Buca Faculty of Education Journal, (30), 206-220.

[19] Hofer B. K. \& Pintrich, P.R. (1997). “The Development of Epistemological Theories: Beliefs about Knowledge and Knowing and Their Relation to Learning", Review of Educational Research, 67 (1), 88-140

[20] İçen, M., İlgan, A. \& Göker, H. (2013). An Analysis of Epistemological Beliefs of Social Sciences Teacher Candidates, Anatolian Journal of Educational Leadership and Instruction, 1 (2), 2-11.

[21] Karhan, İ. (2007). An examination of epistemological beliefs of primary school teachers in terms of their demographic characteristics and use of information technology, Unpublished Ph.D. thesis. Yildiz Technical University Institute of Social Sciences, Istanbul.

[22] Kızılgüneş, B., Tekkaya, C., \& Sungur, S. (2009). Modeling the relations among students' epistemological beliefs, motivation, learning approach, and achievement. The Journal of Educational Research, 102 (4), 243-255. 
[23] Oksal, A., Senșekerci, E., \& Bilgin, A. (2006). Development of central epistemological beliefs scale: Validity and reliability. Journal of Uludag University Faculty of Education, 19(2).

[24] Özden, Y. (2003). Learning and Teaching, Advanced 5. Edition, Ank: Pegem A Publication.

[25] Phan, H. P. (2008). Predicting change in epistemological beliefs, reflective thinking and learning styles: A longitudinal study. British Journal of Educational Psychology, 78, 75-93.

[26] Pieschl S., Stahl, E. ve Bromme, R. (2008), "Epistemological beliefs and self-regulated learning with hypertext', Metacognition Learning 3(3), ss. 17-37.

[27] Sapanc1, A. (2012). The relation among epistemological beliefs and metacognitive levels and academic achievement of teacher candidates. Celal Bayar University The Journal of Social Sciences, 10(1), 311-331.

[28] Schommer, M. (1990). Effects of beliefs about the nature of knowledge on comprehension, Journal of Education Psychology, 82 (3), 498-504.

[29] Schommer, M. (1998). The influence of age and schooling on epistemological beliefs, The British Journal of Educational Psychology, 68, 551-562.

[30] Schommer, M., Mau, W. C., Broohart, S ve Hutter, R (2000), "Understanding middle students' beliefs about knowledge and learning using a multidimensional paradigm", The Journal of Educational Research, 94(2), ss. 120-127.

[31] Sinatra, G. M., \& Kardash, C. A. M. (2004). Teacher candidates' epistemological beliefs, dispositions, and views on teaching as persuasion. Contemporary Educational Psychology, 29, 483- 498.

[32] Sümer, N. (2000). Structural equation models: Basic concepts and sample applications, Turkish Psychology Articles, 3, (6), 49-74.

[33] Şimsek, O. F. (2007). Introduction to structural equation modeling basic concepts and LISREL applications. Ankara: Ekinoks.

[34] Tabachnick, B. G. \& Fidell, L. S. (2001). Using multivariate statistics, Fourth Edition. New York: Harper Collins Publishers.

[35] Taşkın, Ç. Ş. (2012). Epıstemologıcal Belıefs: As Predictors of Preservice Teachers' Learning Approaches. Mustafa Kemal University Journal of Social Sciences Institute, 9(19).

[36] Terzi, A. R. (2005). A research on epistemological beliefs of university students. Afyon Kocatepe University, Journal of Social Sciences, 298-311.

[37] Thomas, J. A. (2008) "Reviving Perry: an analysis of epistemological change by gender and ethnicity among gifted high school students", Gifted Child Quarterly 52(1), ss. 87-98.

[38] Türkan, A., Aydın, H., \& Üner, S. S. (2016). An Examination of the Relation between Epistemological Beliefs and Multicultural Education Attitudes of Teacher Candidates. Elementary Online, 15(1).

[39] Y1lmaz-Tüzün, Ö. \& Topçu, M. S. (2013). Exploration of Preservice Science Teachers\'Epistemological Beliefs, World Views, and Self-Efficacy Considering Gender and Achievement. Elementary Online, 12(3). 